\title{
Lattice defect-enhanced adsorption of arsenic on zirconia nanospheres: A combined experimental and theoretical study
}

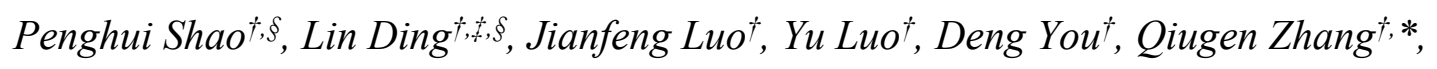
and Xubiao Luo ${ }^{\dagger, *}$

$\dagger$ Key Laboratory of Jiangxi Province for Persistent Pollutants Control and Resources

Recycle, Nanchang Hangkong University, Nanchang 330063, P. R. China

†School of Environmental Science and Engineering, Huazhong University of Science and Technology, Wuhan, Hubei 430074, P. R. China

*Corresponding author: Prof. Xubiao Luo E-mail: luoxubiao@126.com; Prof. Qiugen Zhang, E-mail: niatzqg@nchu.edu.cn.

$\S$ These authors contributed equally. 


\section{Section S1. Synthesis of UiO-66 and UiO-66- $\mathrm{NH}_{2}$}

Specifically, $466.4 \mathrm{mg}$ of $\mathrm{ZrCl}_{4}$ and $332.2 \mathrm{mg}$ of PTA were dissolved in $100 \mathrm{~mL}$ of DMF under ultrasonic stirring for $30 \mathrm{~min}$. The solution was later transferred to an autoclave and heated at $393 \mathrm{~K}$ for $48 \mathrm{~h}$. After cooling to room temperature ( $298 \mathrm{~K})$, the resulting sample was purified several times with DMF and anhydrous methanol and was finally dried overnight at $373 \mathrm{~K}$ under vacuum. The UiO-66- $\mathrm{NH}_{2}$ was prepared by a similar process except $0.1812 \mathrm{~g}$ of 2-aminoterephthalic acid was used instead of PTA.

\section{Section S2. Synthesis of UiO-66-SH}

Firstly, the organic ligand of 2,5-dimercapto-1,4-benzenedicarboxylic acid $\left(\mathrm{H}_{2} \mathrm{DMBD}\right)$ was synthesized (see Scheme S1). $2 \mathrm{~g}$ of 2,5-dihydroxyterephthalic acid diethyl ester (a) and $3.6 \mathrm{~g}$ of DABCO were dissolved in dry DMA $(20 \mathrm{~mL})$ under a nitrogen atmosphere and cooled to $273 \mathrm{~K}$ in an ice bath. $3.8 \mathrm{~g}$ of N,N-dimethylthiocarbamoyl chloride dissolved in dry DMA (10 mL) was added dropwise under nitrogen. The mixture was stirred at room temperature for $16 \mathrm{~h}$. Next, the resulting material (b) was filtered, washed by deionized water $(100 \mathrm{~mL})$, and dried under vacuum. ( ${ }^{1} \mathrm{H}$ NMR (400 MHz, $\left.\mathrm{CDCl}_{3}\right): \delta 7.73(\mathrm{~s}, 2 \mathrm{H}, \mathrm{CHAr}), 4.30\left(\mathrm{q}, \mathrm{J}=7.1 \mathrm{~Hz}, 4 \mathrm{H}, \mathrm{CH}_{2}\right), 3.46(\mathrm{~s}, 6 \mathrm{H}$,

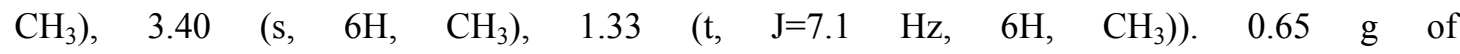
2,5-bis(dimethylthiocarbamoyloxy)terephthalic acid diethyl ester (b) was heated under nitrogen at $498 \mathrm{~K}$ for $1 \mathrm{~h}$. The mixture was cooled to $343 \mathrm{~K}, 20 \mathrm{~mL}$ of EtOH was added and the mixture was further refluxed for 30 min under nitrogen. Pale brown crystals appeared as the sample was slowly cooled to room temperature. The crystals were filtered off, yielding compound (c). $\left({ }^{1} \mathrm{H}\right.$ NMR (400 $\left.\mathrm{MHz}, \delta \mathrm{CDCl}_{3}\right): 8.11(\mathrm{~s}, 2 \mathrm{H}, \mathrm{CHAr}), 4.34\left(\mathrm{q}, \mathrm{J}=7.1 \mathrm{~Hz}, 4 \mathrm{H}, \mathrm{CH}_{2}\right), 3.12\left(\mathrm{~s}, 6 \mathrm{H}, \mathrm{CH}_{3}\right), 3.02(\mathrm{~s}, 6 \mathrm{H}$, 
$\left.\left.\mathrm{CH}_{3}\right), 1.37\left(\mathrm{t}, \mathrm{J}=7.1 \mathrm{~Hz}, 6 \mathrm{H}, \mathrm{CH}_{3}\right)\right) .1 .3 \mathrm{~g}$ of 2,5-bis(dimethylthiocarbamoylsulfanyl)terephthalic acid diethyl ester (c) was dissolved in $40 \mathrm{~mL}$ of degassed $1.3 \mathrm{M} \mathrm{KOH}$ in $\mathrm{EtOH} / \mathrm{H}_{2} \mathrm{O}(1: 1)$, and the mixture was refluxed under a nitrogen atmosphere for $3 \mathrm{~h}$. The reaction mixture was then cooled in ice and concentrated $\mathrm{HCl}(15 \mathrm{~mL})$ was added. A bright yellow precipitate was formed, filtered, and washed extensively with water, yielding the 2,5-dimercapto-1,4-benzenedicarboxylic acid (d). ( ${ }^{1} \mathrm{H}$ NMR (400 MHz, $\left.\mathrm{CD}_{3} \mathrm{OD}\right): \delta 8.02$ (s, 2H, CHAr)).<smiles>CCOC(=O)c1cc(O)c(C(=O)OCC)cc1O</smiles>

(a)

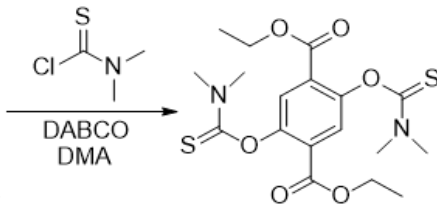

(b)

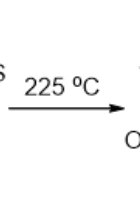

(c)

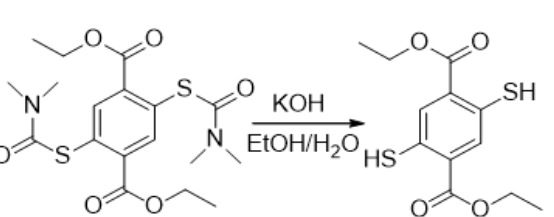

(d)

Scheme S1. Synthesis of 2,5-dimercapto-1,4-benzenedicarboxylic acid.

Then, preparation of UiO-66-SH was performed in $250 \mathrm{~mL}$ round-bottom flask. Briefly, 240mg of $\mathrm{ZrCl}_{4}$ was dissolved in $40 \mathrm{~mL}$ of DMF containing $9.4 \mathrm{~mL}$ of acetic acid with ultrasonic agitation for $30 \mathrm{~min}$ to complete dissolution. $237.5 \mathrm{mg}$ of $\mathrm{H}_{2} \mathrm{DMBD}$ was superadded to the above solution and the mixture was sonicated for $30 \mathrm{~min}$. The solution was then poured into a round-bottom flask under nitrogen condition, and transferred to a pre-heated oven at $403 \mathrm{~K}$ for 36 h. Since the thiol group is easily oxidized, the condition of nitrogen protection can effectively prevent oxidation of thiol groups, so that more thiol-based active adsorption sites can be prepared. Then the faint yellow solids were procured by centrifugation. In order to eliminate the unreacted substrate such as residual ligands $\mathrm{H}_{2} \mathrm{DMBD}$, the precipitate was washed three times by DMF (100 $\mathrm{mL})$ and dichloromethane $(100 \mathrm{~mL})$. Finally, the solid products were filtered and dried for $12 \mathrm{~h}$ at $333 \mathrm{~K}$ under air for removal of attached solvent molecules. 


\section{Section S3. Characterizations}

Morphologies of the synthesized samples were characterized by scanning electron microscopy (SEM) using a Nova Nano SEM450. Powder x-ray diffraction (XRD) patterns of the samples were obtained by a Bruker D8-Advance diffractometer using $\mathrm{Cu} K \alpha$ radiation $(\lambda=1.5418$ Å). Fourier transform infrared (FTIR) spectra were collected by a VERTEX 70 FTIR apparatus. The Brunauer-Emmett-Teller specific surface area (SSA) was measured based on the nitrogen adsorption-desorption isotherm that recorded by the Micromeritics TriStar II 3020. X-ray photoelectron spectroscopy (XPS) measurements were performed on an Axis Ultra (Kratos, XSAM800) XPS spectrometer using Al target (1486.6 eV) X-ray source. Surface charges of adsorbents were measured by a Nano ZS90 Zeta potential analyzer (Malvern, UK).

\section{Section S4. Calculation formula of adsorption capacity}

The amounts of $\mathrm{As}(\mathrm{III}) / \mathrm{As}(\mathrm{V})$ adsorbed on UiO-66-A, UiO-66- $\mathrm{NH}_{2}-\mathrm{A}$ and UiO-66-SH-A were calculated by the following equation:

$$
Q_{e}=\frac{C_{0} V-C_{e} V}{m}
$$

where $Q_{\mathrm{e}}(\mathrm{mg} / \mathrm{g})$ represents the adsorption capacity; $C_{0}(\mathrm{mg} / \mathrm{L})$ is the initial concentration of $\mathrm{As}(\mathrm{III})$ and $\mathrm{As}(\mathrm{V})$ ions; $C_{\mathrm{e}}(\mathrm{mg} / \mathrm{L})$ is the equilibrium concentration of $\mathrm{As}(\mathrm{III})$ and $\mathrm{As}(\mathrm{V})$ ions; $m$ (g) is the mass of adsorbents; and $V(\mathrm{~L})$ is the volume of the $\mathrm{As}(\mathrm{III})$ and $\mathrm{As}(\mathrm{V})$ ions solution.

\section{Section S5. Equations of Langmuir isotherm model}

The equation of Langmuir isotherm is listed as following: 


$$
\frac{C_{e}}{Q_{e}}=\frac{C_{e}}{Q_{m}}+\frac{1}{K_{L} Q_{m}}
$$

Where $Q_{\mathrm{m}}(\mathrm{mg} / \mathrm{g})$ is the maximum adsorption capacity; $K_{\mathrm{L}}(\mathrm{L} / \mathrm{mg})$ is the Langmuir constant that represents the affinity between solute and adsorbent.

\section{Section S6. Dubinin-Radushkevich (D-R) isotherm model}

The D-R equation is expressed by following equation:

$$
\operatorname{In} Q_{e}=\operatorname{In} Q_{m}-K \varepsilon^{2}
$$

Where $Q_{\mathrm{e}}(\mathrm{mg} / \mathrm{g})$ and $Q_{\mathrm{m}}(\mathrm{mg} / \mathrm{g})$ are the equilibrium and theoretical saturation capacity, respectively; $K\left(\mathrm{~mol}^{2} / \mathrm{kJ}^{2}\right)$ is the activity coefficient related to mean free energy of adsorption, and $\varepsilon(\mathrm{kJ} / \mathrm{mol})$ is the Polanyi potential:

$$
\varepsilon=R \operatorname{TIn}\left(1+\frac{1}{C_{e}}\right)
$$

Where $R$ is the universal gas constant $(8.314 \mathrm{~J} /(\mathrm{mol} \mathrm{K})) ; T(\mathrm{~K})$ is Kelvin temperature; and $C_{\mathrm{e}}$ $(\mathrm{mol} / \mathrm{L})$ is the equilibrium concentration. The $\mathrm{D}-\mathrm{R}$ model is mainly used to estimate the average free energy of adsorption $E(\mathrm{~kJ} / \mathrm{mol})$, which is expressed using the following equation:

$$
E=\frac{1}{\sqrt{2 K}}
$$

\section{Section S7. Equations of adsorption thermodynamics}

The thermodynamic parameters including standard free energy change $\Delta G^{0}(\mathrm{~kJ} / \mathrm{mol})$, enthalpy change $\Delta H^{0}(\mathrm{~kJ} / \mathrm{mol})$ and entropy change $\Delta S^{0}(\mathrm{~kJ} /(\mathrm{mol} \mathrm{K}))$ were calculated by the following equations: 


$$
\begin{aligned}
\Delta G^{0} & =-R T \ln K \\
\ln K & =-\Delta H^{0} / R T+\Delta S^{0} / R
\end{aligned}
$$

Where $R$ is the gas constant $(8.314 \mathrm{~J} /(\mathrm{mol} \mathrm{K})), T$ is the absolute temperature. $K$ is the thermodynamic equilibrium constant in the adsorption process, which was determined using the method of Khan and Singh by plotting $\ln \left(q_{e} / C_{e}\right)$ versus $q_{e}$ and extrapolating to zero $q_{e}$. Meanwhile, $\Delta S^{0}$ and $\Delta H^{0}$ are the intercept and slope, respectively.

\section{Section S8. Equations of Pseudo-first-order and pseudo-second-order kinetics models}

The equations of Pseudo-first-order and pseudo-second-order kinetics are listed as following:

$$
\begin{aligned}
& \operatorname{In}\left(Q_{e}-Q_{t}\right)=\operatorname{In} Q_{e}-K_{1} t \\
& \frac{t}{Q_{t}}=\frac{1}{K_{2} Q_{e}{ }^{2}}+\frac{t}{Q_{e}} \\
& h_{0}=K_{2} Q_{e}{ }^{2}
\end{aligned}
$$

Where $Q_{\mathrm{t}}(\mathrm{mg} / \mathrm{g})$ is the amount of adsorbate at any time; $Q_{\mathrm{e}}(\mathrm{mg} / \mathrm{g})$ is the amount of adsorbate at equilibrium; $K_{1}\left(\mathrm{~min}^{-1}\right)$ is the pseudo-first-order rate constant; $K_{2}(\mathrm{~g} /(\mathrm{mg} \cdot \mathrm{min}))$ is the pseudo-second-order constant; and $h_{0}(\mathrm{mg} /(\mathrm{g} \cdot \mathrm{min}))$ is the initial adsorption rate.

\section{Section S9. Optimization of annealing temperature}

According to our preliminary results, it was found that the annealing temperature exhibited a significant influence on the phase structure of the $\mathrm{ZrO}_{2}$ nanospheres. Figure $\mathbf{S 1}$ shows the XRD patterns of $\mathrm{ZrO}_{2}$ prepared by annealing the UiO-66, UiO-66- $\mathrm{NH}_{2}$ and UiO-66-SH at different 
temperatures. When the annealing temperature was set at $600{ }^{\circ} \mathrm{C}$, the phases of all the samples were amorphous. When the temperature increased to $900{ }^{\circ} \mathrm{C}$, the crystallinity of all the samples have been improved and a pure phase of cubic $\mathrm{ZrO}_{2}$ ( $\left.\mathrm{PDF} \# 49-1642\right)$ can be observed in these samples. Interestingly, the monoclinic phase of $\mathrm{ZrO}_{2}$ (PDF\#37-1484) can be achieved when the annealing temperature further increased to $1200{ }^{\circ} \mathrm{C}$. After that, the uptake capacities of $\mathrm{ZrO}_{2}$ obtained at different annealing temperatures have been evaluated in the adsorption of $\operatorname{As}(\mathrm{III}) / \mathrm{As}(\mathrm{V})$, as shown in Figure S2. It demonstrates that all the samples those annealing at 900 ${ }^{\circ} \mathrm{C}$ have possessed higher adsorptivity for the $\mathrm{As}(\mathrm{III}) / \mathrm{As}(\mathrm{V})$. As such, the optimal annealing temperature was set at $900{ }^{\circ} \mathrm{C}$ for synthesis of adsorbent.
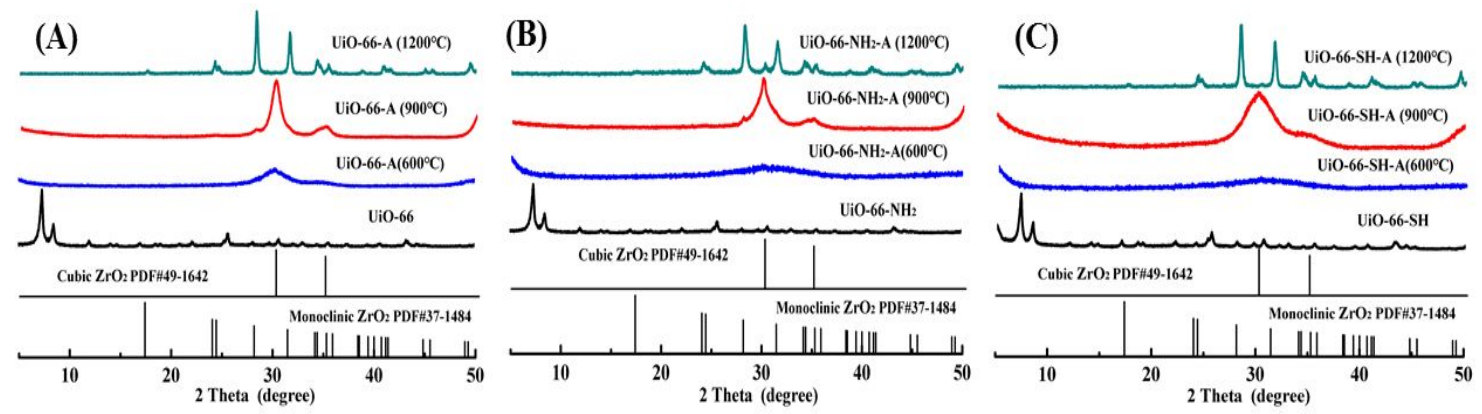

Figure S1. XRD patterns of $\mathrm{ZrO}_{2}$ prepared by annealing UiO-66 (A), UiO-66- $\mathrm{NH}_{2}$ (B) and UiO-66-SH (C) at different temperatures.

(A)

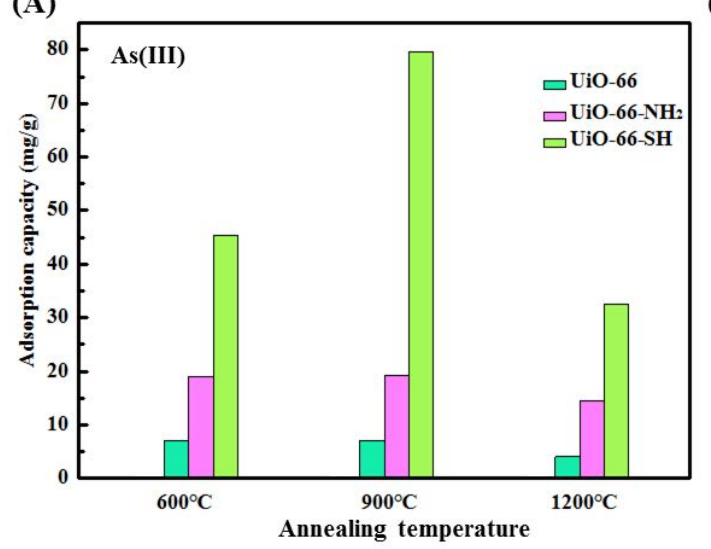

(B)

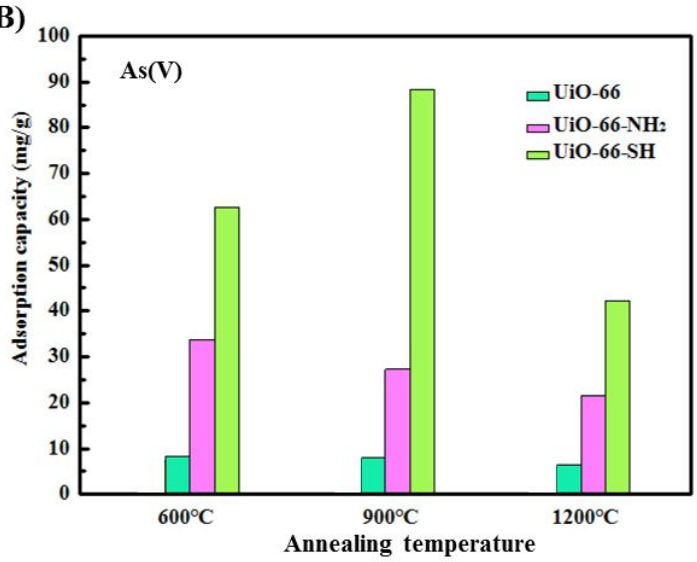

Figure S2. Adsorption capacities of $\mathrm{As}(\mathrm{III})(\mathrm{A})$ and $\mathrm{As}(\mathrm{V})(\mathrm{B})$ on $\mathrm{ZrO}_{2}$ prepared by annealing UiO-66, UiO-66- $\mathrm{NH}_{2}$ and UiO-66-SH at different temperatures. 

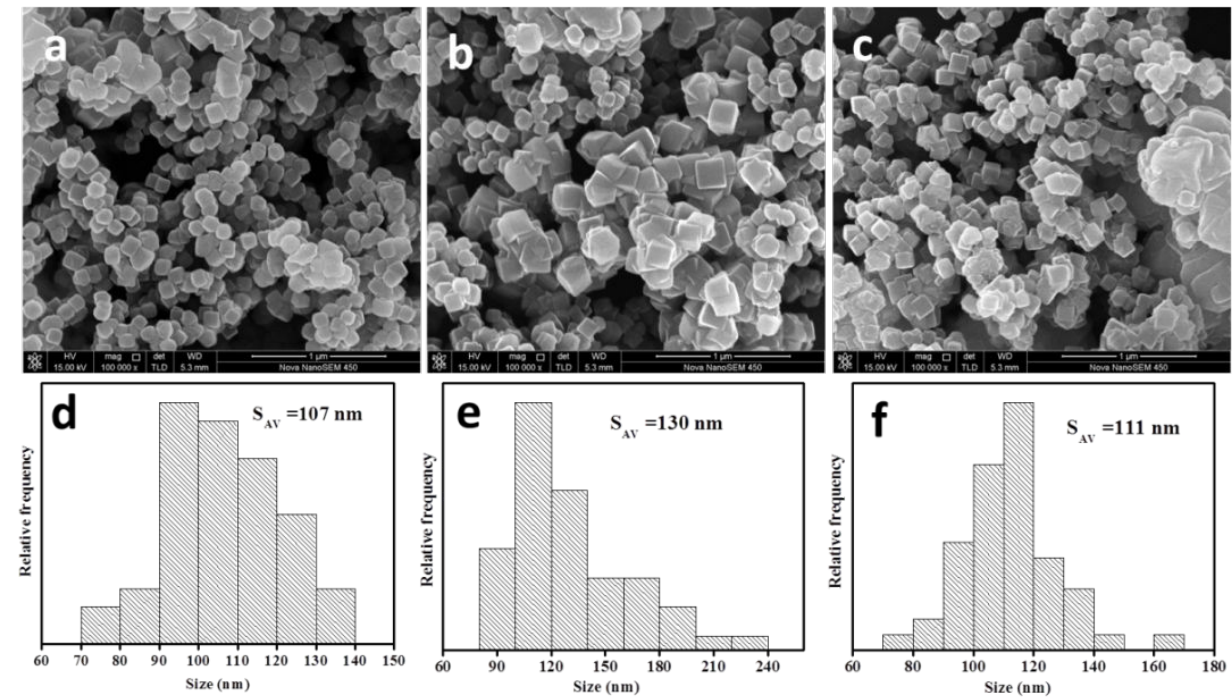

Figure S3. SEM images and the corresponding size distributions of the samples: (a) and (d) for the UiO-66; (b) and (e) for the UiO-66- $\mathrm{NH}_{2}$; (c) and (f) for the UiO-66-SH.

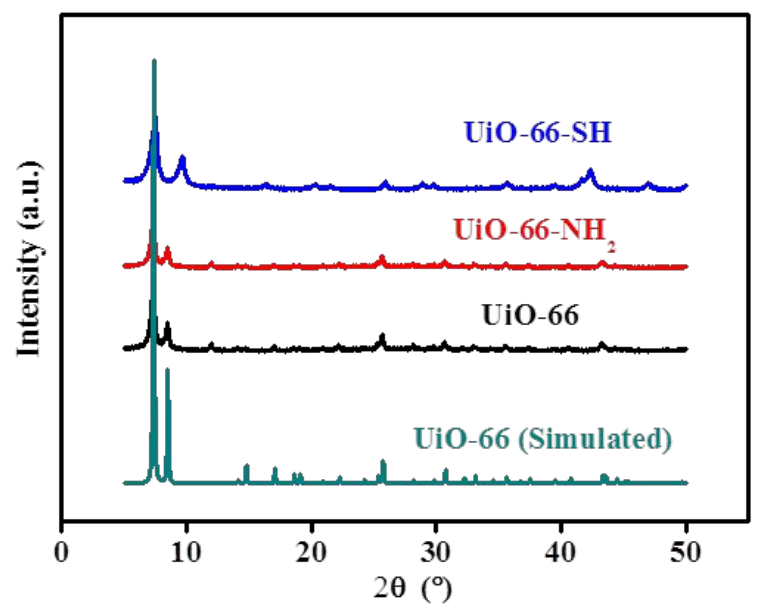

Figure S4. XRD patterns of the UiO-66, UiO-66- $\mathrm{NH}_{2}$ and UiO-66-SH. 


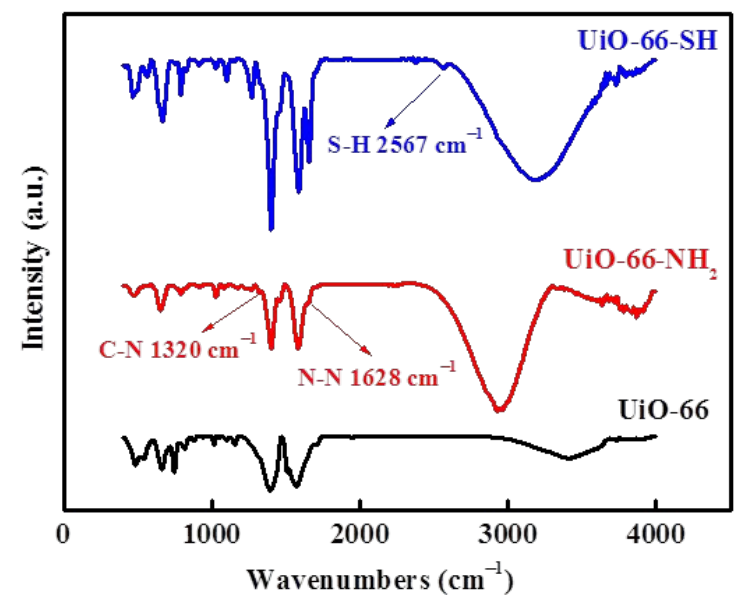

Figure S5. IR spectra of the UiO-66, UiO-66- $\mathrm{NH}_{2}$ and UiO-66-SH.

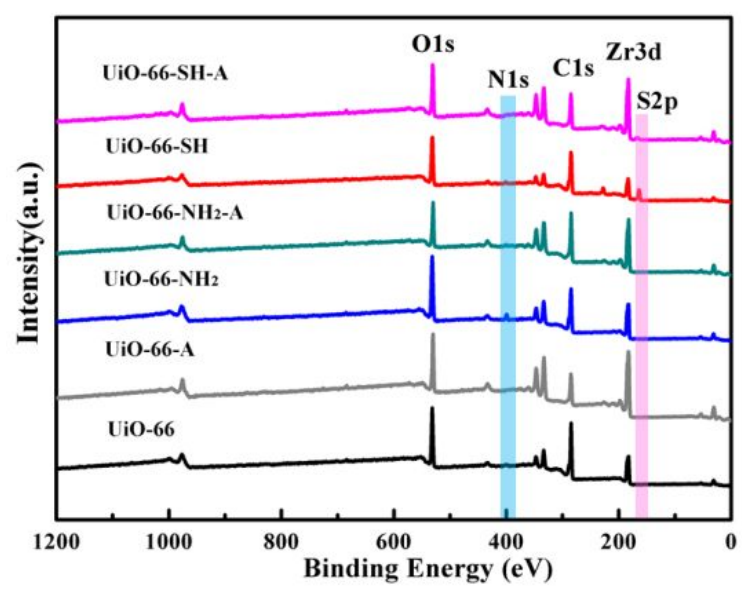

Figure S6. XPS spectra for raw and annealed UiO-66, UiO-66- $\mathrm{NH}_{2}$ and UiO-66-SH.
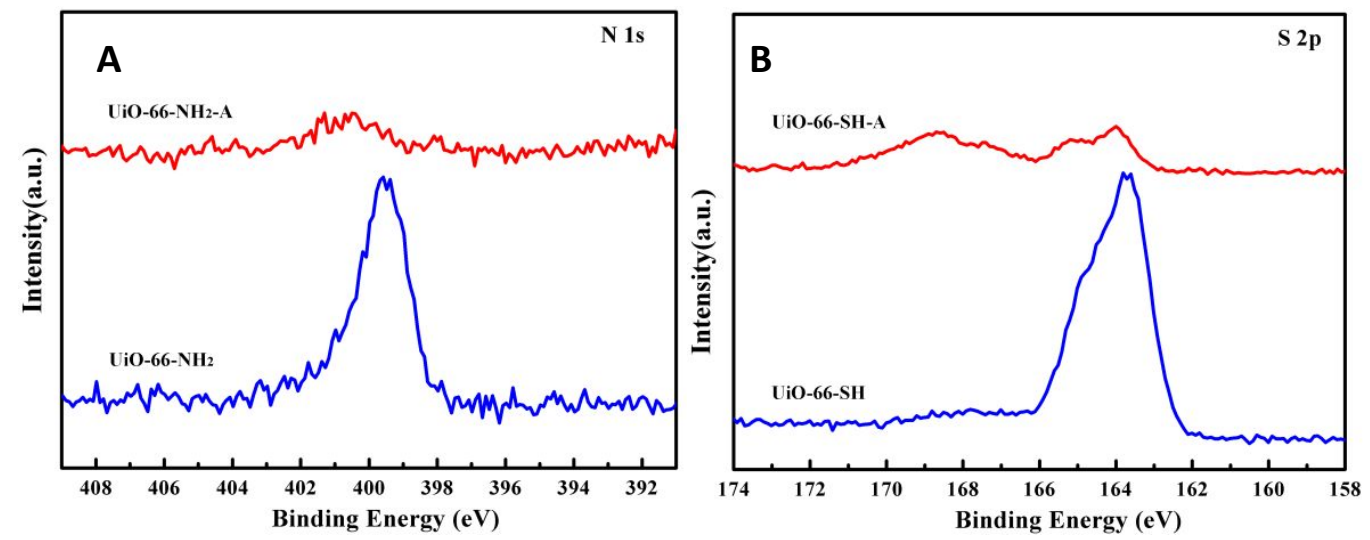

Figure S7. XPS spectra for N 1s and S 2p of raw and annealed UiO-66- $\mathrm{NH}_{2}$ (A) and UiO-66-SH

(B). 


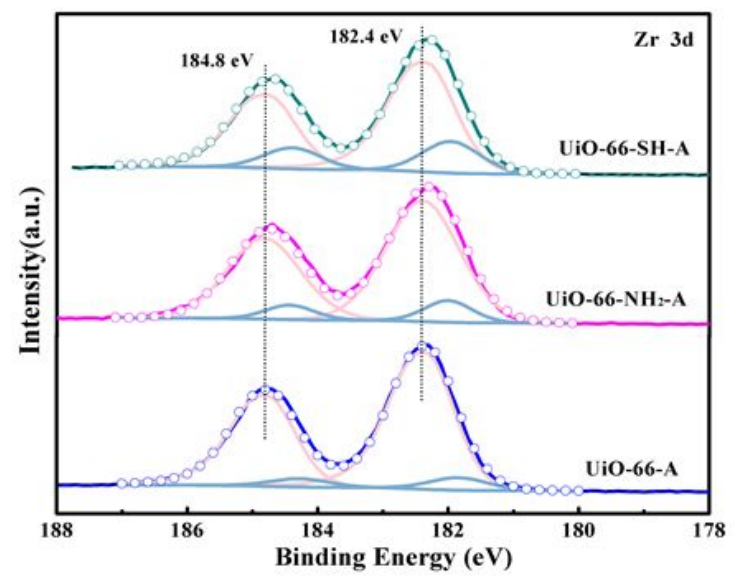

Figure S8. Zr 3d XPS spectra of the annealed samples.
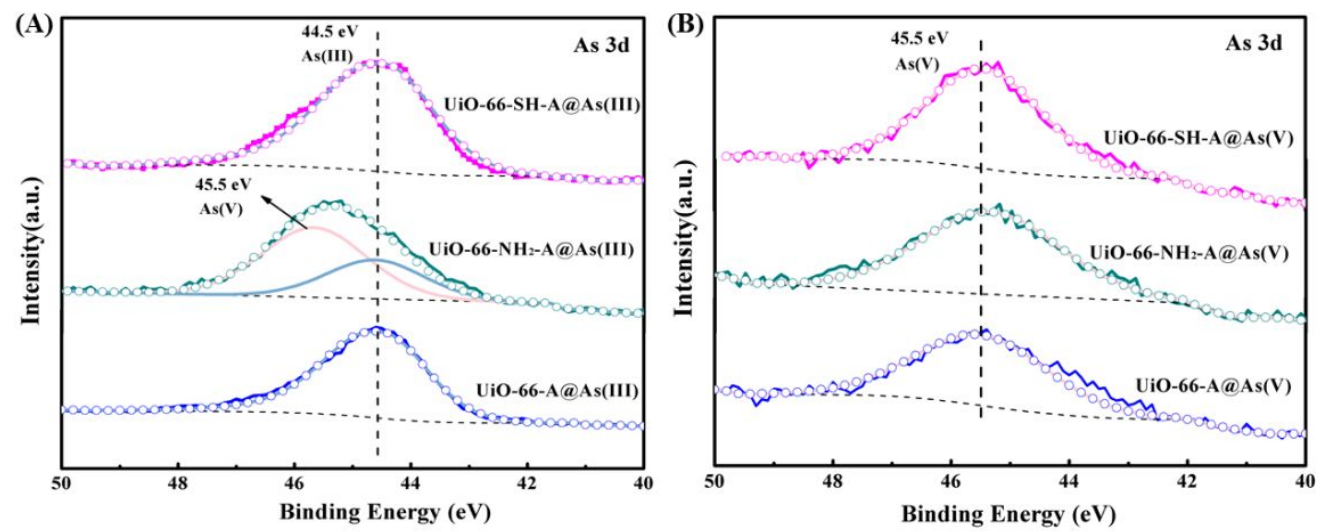

Figure S9. XPS spectra for As 3d of as-made $\mathrm{ZrO}_{2}$ before and after adsorption of $\mathrm{As}$ (III) (A) and $\mathrm{As}(\mathrm{V})(\mathrm{B})$. 


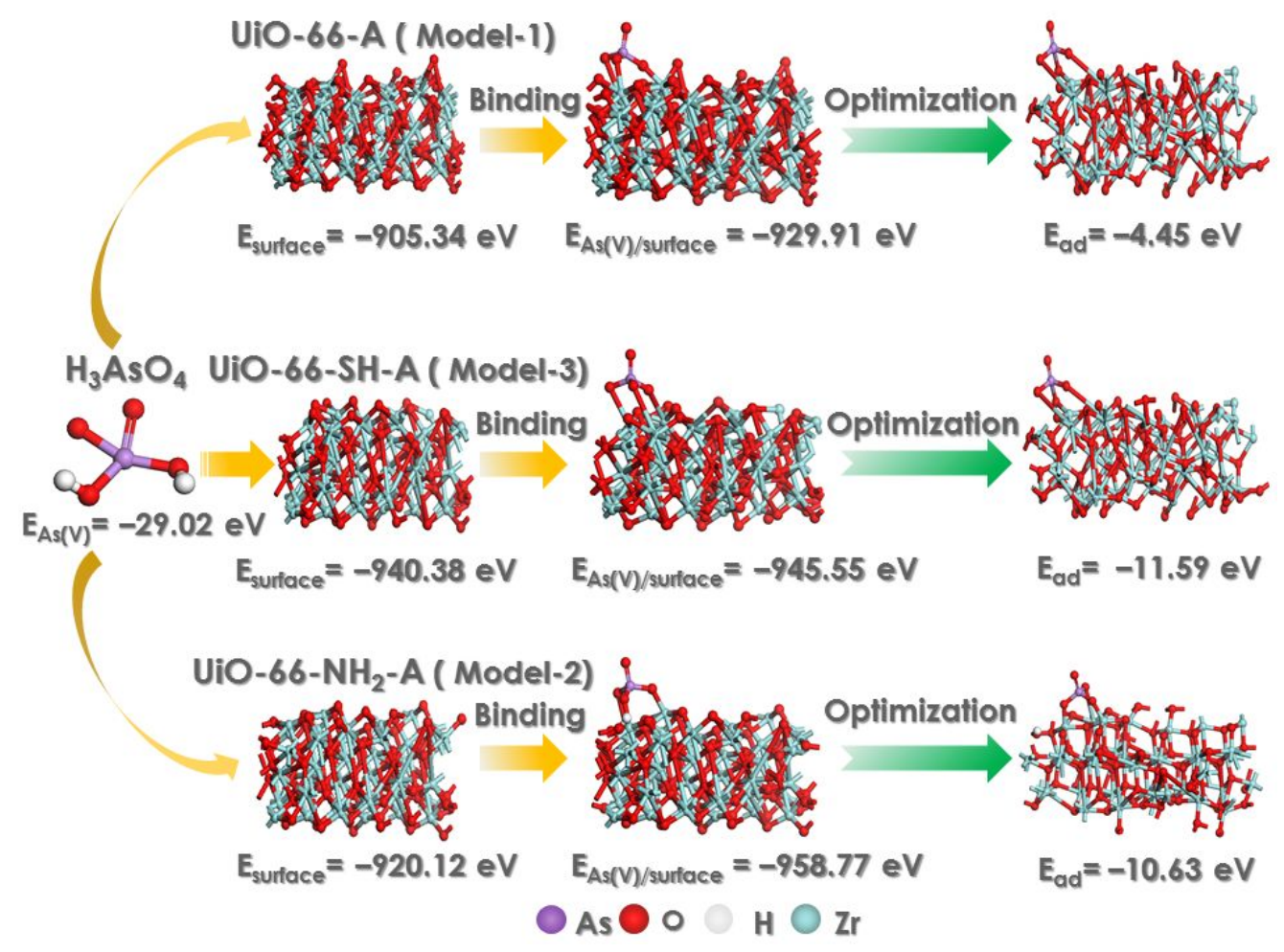

Figure S10. DFT calculation of $\mathrm{As}(\mathrm{V})$ adsorption on the as-synthesized $\mathrm{ZrO}_{2}$ with different lattice defect

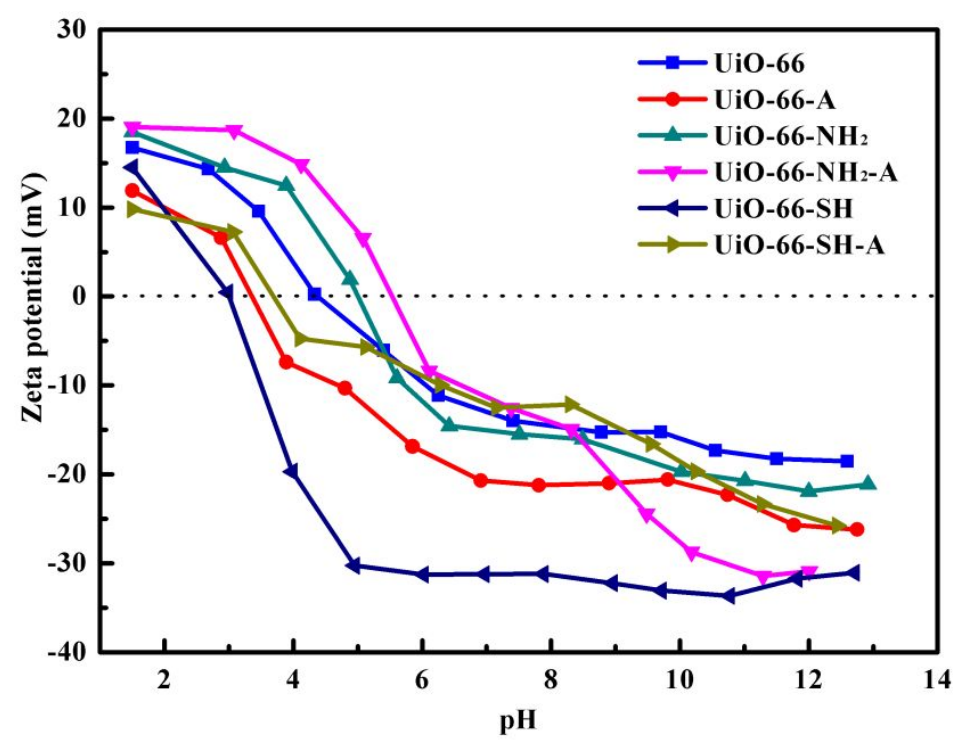

Figure S11. Zeta potentials of the sample measured at different $\mathrm{pH}$ values. 

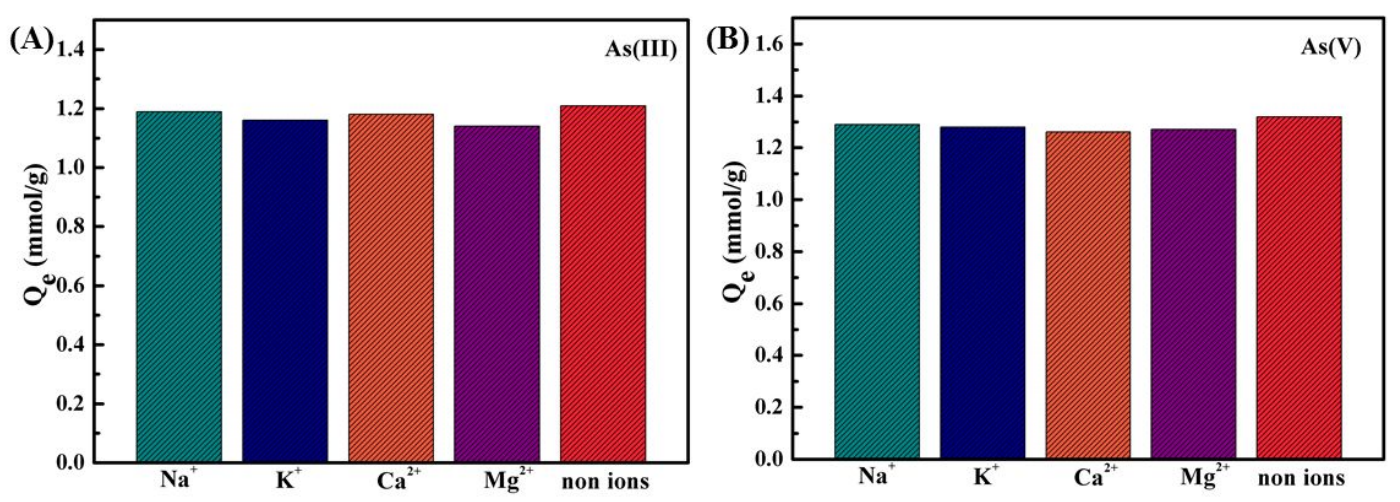

Figure S12. Effects of cations on the adsorption of (A) As(III) and (B) As(V) by UiO-66-SH-A.

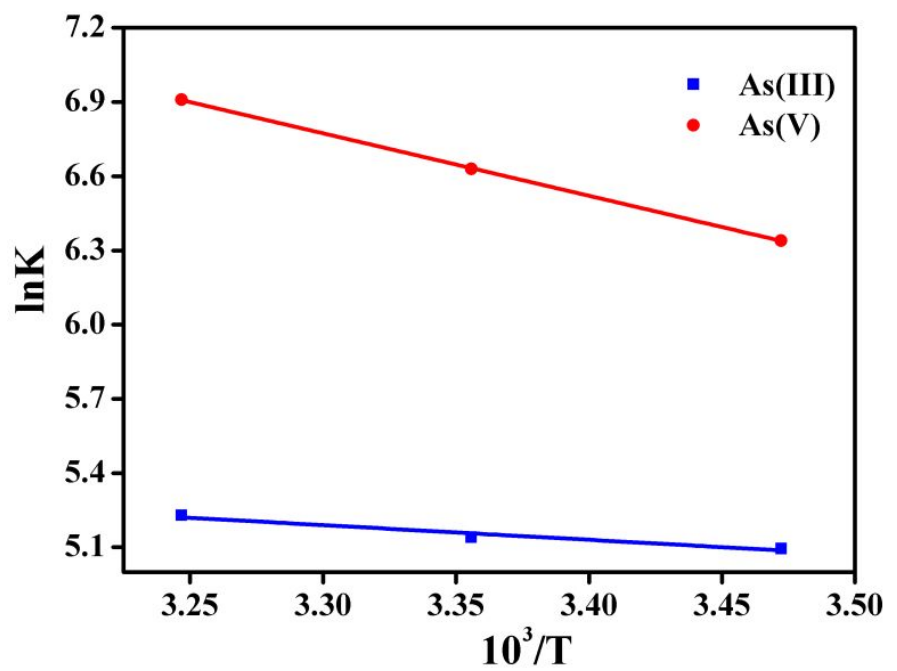

Figure S13. Fitting plots of $\ln K$ versus $10^{3} / T$ for the calculation of thermodynamic parameters. 
Table S1. The calculation results of O 1s XPS

\begin{tabular}{|c|c|c|c|}
\hline Samples & $\mathrm{O}_{\text {latt }}(\%)$ & $\mathrm{O}_{\mathrm{ads}}(\%)$ & $\mathrm{O}_{\mathrm{vac}}(\%)$ \\
\hline UiO-66-A & 65.91 & 28.15 & 5.94 \\
\hline UiO-66-A@As(III) & 62.25 & 33.87 & 3.88 \\
\hline UiO-66-A@As(V) & 60.37 & 36.6 & 3.03 \\
\hline $\mathrm{UiO}-66-\mathrm{NH}_{2}-\mathrm{A}$ & 59.40 & 29.07 & 11.54 \\
\hline UiO-66-NH $-\mathrm{N}-\mathrm{A} @ \mathrm{As}(\mathrm{III})$ & 59.94 & 36.46 & 3.60 \\
\hline UiO-66-NH2-A@As(V) & 58.30 & 38.84 & 2.86 \\
\hline UiO-66-SH-A & 54.21 & 29.28 & 16.51 \\
\hline UiO-66-SH-A@As(III) & 56.69 & 40.26 & 3.04 \\
\hline UiO-66-SH-A@As(V) & 54.66 & 42.05 & 3.29 \\
\hline
\end{tabular}

Table S2. Adsorption isotherm fitting parameters of As(III) on different adsorbents

\begin{tabular}{|c|c|c|c|}
\hline \multirow{2}{*}{ Adsorbents } & \multicolumn{3}{|c|}{ Langmuir model } \\
\hline & $Q_{\mathrm{m}}(\mathrm{mg} / \mathrm{g})$ & $K_{\mathrm{L}}(\mathrm{L} / \mathrm{mg})$ & $R^{2}$ \\
\hline $\mathrm{ZrO}_{2}$ & 6.65 & 0.027 & 0.999 \\
\hline UiO-66-A & 7.42 & 0.038 & 0.999 \\
\hline $\mathrm{UiO}-66-\mathrm{NH}_{2}-\mathrm{A}$ & 23.07 & 0.013 & 0.985 \\
\hline UiO-66-SH-A & 90.91 & 0.015 & 0.970 \\
\hline
\end{tabular}


Table S3. Adsorption isotherm fitting parameters of $\mathrm{As}(\mathrm{V})$ on different adsorbents

\begin{tabular}{cccc}
\hline & \multicolumn{3}{c}{ Langmuir model } \\
Adsorbents & $Q_{\mathrm{m}}(\mathrm{mg} / \mathrm{g})$ & $K_{\mathrm{L}}(\mathrm{L} / \mathrm{mg})$ & $R^{2}$ \\
\cline { 2 - 4 } $\mathrm{ZrO}_{2}$ & 7.38 & 0.021 & 0.998 \\
UiO-66-A & 8.61 & 0.027 & 0.997 \\
UiO-66-NH & & 0.011 & 0.967 \\
UiO-66-SH-A & 33.85 & & 0.983 \\
\hline
\end{tabular}

Table S4. Adsorption isotherm fitting parameters of As(III) on different adsorbents

\begin{tabular}{ccccc}
\hline & \multicolumn{4}{c}{ Dubinin-Radushkevich (D-R) isotherm model } \\
\cline { 2 - 5 } Adsorbents & $Q_{\mathrm{m}}$ & $K$ & $E$ & $R^{2}$ \\
& $(\mathrm{~mol} / \mathrm{kg})$ & $\left(\mathrm{mol}^{2} / \mathrm{kJ}^{2}\right)$ & $(\mathrm{kJ} / \mathrm{mol})$ & \\
\hline $\mathrm{ZrO}_{2}$ & 0.00015 & 0.0036 & 11.79 & 0.785 \\
UiO-66-A & 0.00014 & 0.0024 & 14.43 & 0.937 \\
UiO-66-NH & & & 11.95 & 0.935 \\
UiO-A66-SH-A & 0.00044 & 0.0035 & & 0.909 \\
\hline
\end{tabular}


Table S5. Adsorption isotherm fitting parameters of $\mathrm{As}(\mathrm{V})$ on different adsorbents

\begin{tabular}{ccccc}
\hline & \multicolumn{4}{c}{ Dubinin-Radushkevich (D-R) isotherm model } \\
\cline { 2 - 5 } Adsorbents & $Q_{\mathrm{m}}$ & $K$ & $E$ & $R^{2}$ \\
& $(\mathrm{~mol} / \mathrm{kg})$ & $\left(\mathrm{mol}^{2} / \mathrm{kJ}^{2}\right)$ & $(\mathrm{kJ} / \mathrm{mol})$ & \\
\hline $\mathrm{ZrO}_{2}$ & 0.00019 & 0.0043 & 10.78 & 0.954 \\
UiO-66-A & 0.00017 & 0.0028 & 13.36 & 0.975 \\
UiO-66-NH & & & 11.32 & 0.924 \\
UiO-66-SH-A & 0.00068 & 0.0039 & & 0.949 \\
\hline
\end{tabular}

Table S6. Comparison of adsorption equilibrium time with the reported nanostructure adsorbents.

\begin{tabular}{ccc}
\hline Adsorbents & Equilibrium time & Reference \\
\hline Multiwall carbon nanotube-zirconia nanohybrid & As(III) 300 min; As(V) 100 min & 42 \\
D401-Zr & As(III) 1440 min; As(V) 420 & 45 \\
ZrO ${ }_{2}$ embedded in carbon nanowires & As(III) 40 min; As(V) 30 min & 13 \\
Amorphous ZrO nanoparticles & As(III) 300 min; As(V) 500 min & 14 \\
Zirconia nanoparticle & As(III) 2880 min & 48 \\
Zirconium immobilized nano-scale carbon & As(V) 1800 min & 49 \\
UiO-66-SH-A & As(V) 30 min; As(III) 30 min & this study \\
\hline
\end{tabular}


Table S7. Fitting results using the kinetic models in the adsorption of As(III)

\begin{tabular}{|c|c|c|c|c|c|c|c|}
\hline \multirow{2}{*}{ Adsorbents } & \multicolumn{3}{|c|}{ Pseudo-first-order } & \multicolumn{4}{|c|}{ Pseudo-second-order kinetics } \\
\hline & $\begin{array}{c}K_{1} \\
\left(\mathrm{~min}^{-1}\right)\end{array}$ & $\begin{array}{c}Q_{e} \\
(\mathrm{mg} / \mathrm{g})\end{array}$ & $R^{2}$ & $\begin{array}{c}K_{2} \\
\left(\mathrm{~g} \mathrm{mg}^{-1} \mathrm{~min}^{-1}\right)\end{array}$ & $\begin{array}{c}Q_{e} \\
(\mathrm{mg} / \mathrm{g})\end{array}$ & $\begin{array}{c}h_{o} \\
\left(\mathrm{mg} \mathrm{g}^{-1} \min ^{-1}\right)\end{array}$ & $R^{2}$ \\
\hline $\mathrm{ZrO}_{2}$ & 0.173 & 5.67 & 0.97 & 0.024 & 6.44 & 0.997 & 0.99 \\
\hline UiO-66-A & 0.198 & 6.76 & 0.97 & 0.025 & 7.42 & 1.378 & 0.99 \\
\hline $\mathrm{UiO}-66-\mathrm{NH}_{2}-\mathrm{A}$ & 0.333 & 16.82 & 0.95 & 0.02 & 18.08 & 6.54 & 0.99 \\
\hline UiO-66-SH-A & 0.547 & 77.45 & 0.97 & 0.013 & 79.36 & 81.88 & 0.99 \\
\hline
\end{tabular}

Table S8. Fitting results using the kinetic models in the adsorption of As(V)

\begin{tabular}{|c|c|c|c|c|c|c|c|}
\hline \multirow[b]{2}{*}{ Adsorbents } & \multicolumn{3}{|c|}{ Pseudo-first-order kinetics } & \multicolumn{4}{|c|}{ Pseudo-second-order kinetics } \\
\hline & $\begin{array}{c}K_{1} \\
\left(\mathrm{~min}^{-1}\right)\end{array}$ & $\begin{array}{c}Q_{e} \\
(\mathrm{mg} / \mathrm{g})\end{array}$ & $R^{2}$ & $\begin{array}{c}K_{2} \\
\left(\mathrm{~g} \mathrm{mg}^{-1} \mathrm{~min}^{-1}\right)\end{array}$ & $\begin{array}{c}Q_{e} \\
(\mathrm{mg} / \mathrm{g})\end{array}$ & $\begin{array}{c}h_{o} \\
\left(\mathrm{mg} \mathrm{g}^{-1} \min ^{-1}\right)\end{array}$ & $R^{2}$ \\
\hline $\mathrm{ZrO}_{2}$ & 0.171 & 7.13 & 0.975 & 0.019 & 8.06 & 1.24 & 0.99 \\
\hline UiO-66-A & 0.185 & 8.18 & 0.974 & 0.024 & 8.87 & 1.85 & 0.99 \\
\hline $\mathrm{UiO}-66-\mathrm{NH}_{2}-\mathrm{A}$ & 0.207 & 25.53 & 0.954 & 0.007 & 28.90 & 5.85 & 0.99 \\
\hline UiO-66-SH-A & 0.480 & 87.87 & 0.979 & 0.011 & 89.29 & 87.70 & 0.99 \\
\hline
\end{tabular}


Table S9. Adsorption thermodynamic parameters forthe As adsorption by UiO-66-SH-A.

\begin{tabular}{|c|c|c|c|c|}
\hline Adsorbent & $\mathbf{T}(\mathbf{K})$ & $\begin{array}{c}\Delta G_{0} \\
(\mathrm{~kJ} / \mathrm{mol})\end{array}$ & $\begin{array}{c}\Delta H_{0} \\
(\mathrm{~kJ} / \mathrm{mol})\end{array}$ & $\begin{array}{c}\Delta S_{0} \\
(\mathrm{~kJ} /(\mathrm{mol} \mathrm{K}))\end{array}$ \\
\hline \multirow{4}{*}{ As(III) } & 288.15 & -12.20 & \multirow{3}{*}{4.93} & \multirow{3}{*}{0.12} \\
\hline & 298.15 & -12.74 & & \\
\hline & 308.15 & -13.39 & & \\
\hline & 288.15 & -15.10 & & \multirow{3}{*}{0.55} \\
\hline \multirow[t]{2}{*}{$\mathrm{As}(\mathrm{V})$} & 298.15 & -16.42 & 21.01 & \\
\hline & 308.15 & -17.68 & & \\
\hline
\end{tabular}

